\title{
BMJ Cost of illness of patient-reported OPen adverse drug events: a population-based cross-sectional survey
}

\author{
Hanna Gyllensten, ${ }^{1}$ Clas Rehnberg, ${ }^{2}$ Anna K Jönsson, ${ }^{3}$ Max Petzold, ${ }^{4}$ \\ Anders Carlsten, ${ }^{1,5}$ Karolina Andersson Sundell ${ }^{1,6}$
}

To cite: Gyllensten $\mathrm{H}$, Rehnberg C, Jönsson AK, et al. Cost of illness of patient-reported adverse drug events: a population-based cross-sectional survey. BMJ Open 2013:3:e002574. doi:10.1136/bmjopen-2013002574

- Prepublication history for this paper is available online. To view these files please visit the journal online (http://dx.doi.org/10.1136/ bmjopen-2013-002574).

Received 8 January 2013 Revised 2 May 2013 Accepted 15 May 2013

This final article is available for use under the terms of the Creative Commons Attribution Non-Commercial 2.0 Licence; see http://bmjopen.bmj.com

For numbered affiliations see end of article.

\section{Correspondence to} Hanna Gyllensten; hanna.gyllensten@nhv.se

\section{ABSTRACT}

Objectives: To estimate the cost of illness (COI) of individuals with self-reported adverse drug events (ADEs) from a societal perspective and to compare these estimates with the $\mathrm{COI}$ for individuals without $A D E$. Furthermore, to estimate the direct costs resulting from two ADE categories, adverse drug reactions (ADRs) and subtherapeutic effects of medication therapy (STE).

Design: Cross-sectional study.

Setting: The adult Swedish general population.

Participants: The survey was distributed to a random sample of 14000 Swedish residents aged 18 years and older, of which 7099 responded, 1377 reported at least one ADE and 943 reported an ADR or STE.

Main outcome measures: Societal $\mathrm{COI}$, including direct and indirect costs, for individuals with at least one self-reported $A D E$, and the direct costs for prescription drugs and healthcare use resulting from self-reported ADRs and STEs were estimated during 30 days using a bottom-up approach.

Results: The economic burden for individuals with ADEs were $(95 \% \mathrm{Cl}) 442.7$ to 599.8 international dollars (Int\$), of which direct costs were Int\$ 279.6 to $420.0(67.1 \%)$ and indirect costs were Int\$ 143.0 to $199.8(32.9 \%)$. The average COI was higher among those reporting ADEs compared with other respondents (COI: Int\$ 442.7 to 599.8 versus Int\$ 185.8 to 231.2). The $\mathrm{COI}$ of respondents reporting at least one ADR or STE was Int\$ 468.9 to 652.9. Direct costs resulting from ADRs or STEs were Int\$ 15.0 to 48.4. The reported resource use occurred both in hospitals and outside in primary care.

Conclusions: Self-reported ADRs and STEs cause resource use both in hospitals and in primary care. Moreover, ADEs seem to be associated with high overall $\mathrm{COI}$ from a societal perspective when comparing respondents with and without ADEs. There is a need to further examine this relationship and to study the indirect costs resulting from ADEs.

\section{INTRODUCTION}

Adverse drug event (ADE), "an injury resulting from medical intervention related to a

\section{ARTICLE SUMMARY}

Article focus

- Adverse drug events (ADEs) have been reported not only to cause harm but also resource use from patients attending hospitals.

- Even though ADEs have also been identified outside hospitals, little is known about the associated resource use.

- Thus, we conducted a population-based survey to identify the economic burden of diseases in individuals with ADEs and compare it with those without ADEs.

Key messages

- Our study suggests high overall costs-of-illness for individuals with self-reported ADEs, which are estimated to be more than 500 international dollars (Int\$) per person per month in Sweden when including those with adverse drug reactions (ADRs), drug dependence, drug intoxications, subtherapeutic effects of medication therapy (STE) and untreated indications.

- The estimated direct costs for prescribed drugs and healthcare use resulting from treatment of two of the ADE categories, that is, ADRs and STE, were 30 Int\$ per person per month. This corresponds to more than $10 \%$ of all costs for prescribed drugs and healthcare use among these individuals.

- A large proportion (56\%) of the healthcare resource use in respondents with ADEs occurred in the outpatient setting.

Strengths and limitations of this study

- The main strength is the population-based design, including outpatient and inpatient healthcare, drug use, social services and transportation, lost productivity from both respondents and relatives and health-related quality of life.

- The main limitation of the study is the response rate $(50 \%)$, where some groups were somewhat under-represented in the analysis.

drug,"1 has been identified as a public-health problem that causes harm to patients and considerable resource use. According to 
previous research, 5-6\% of hospitalisations are drug-related, ${ }^{2}{ }^{3}$ and hospitalised patients experiencing adverse drug effects cause additional hospital costs of USD 2284-5640/patient (in 2000 values). ${ }^{4}$ Little is known about the corresponding costs outside hospitals, ${ }^{45}$ or the magnitude of the problem in the general public, although patient-reported adverse drug reactions (ADR) have been reported to affect $6 \%$ of the Swedish population. ${ }^{6}$

The cost of illness (COI) is the economic burden of disease or diseases to the society. The distribution of cost items in the COI can be used to judge the financial relevance of a specific health issue in relation to other public-health problems, and to study the development of the associated resource use over time for different actors in the healthcare system. ${ }^{7}$ Information about COI could also be useful for developing future intervention studies to address ADEs and to retrieve the costs for modelling, for example, cost-effectiveness of drug use in the general public.

Thus, we conducted a population-based survey to study self-reported ADEs. In ADEs, we included ADRs, subtherapeutic effects of medication therapy (STE), drug dependence, drug intoxications and untreated indications. This deviates from the common ADE inclusions used in many previous studies, focusing on ADRs and medication errors, ${ }^{3}$ but were developed from exploring also, for example, drug-related problems that may cause drug-related morbidity. The aim of the current study was to estimate and compare the COI of individuals with and without self-reported ADEs, from a societal perspective. A secondary aim was to estimate the direct costs resulting from two ADE categories, ADRs and STEs. Additional results for prevalence and preventability of self-reported ADEs are reported elsewhere. ${ }^{8}$

\section{METHODS}

\section{Study design}

We conducted a population-based observational retrospective COI study of self-reported ADEs from a crosssectional survey. The COI was prevalence-based and measured from a societal perspective, including direct and indirect costs during the 30 day study period. Costs were measured using a bottom-up approach using unit costs for self-reported resource use and productivity loss from short-term sick leave and informal care. Intangibles were approximated using health-related quality of life.

\section{ADE definitions}

The terminology within patient safety related to drug therapy varies. ${ }^{10}$ ADEs have, for example, been defined as events that occur during drug treatment without a causal relationship to the drug ${ }^{11}$ or, according to the definition used in this study, ${ }^{1}$ that indicate a relationship between the treatment and the negative outcome. From a public-health perspective, there is a need to describe the epidemiology and negative consequences of drug therapy, as a complement to measures of its beneficial effects. ADR reporting has recently been expanded to include all suspected ADRs, including overdose, misuse, abuse, medication errors and reactions associated with occupational exposure. ${ }^{12}$ Thus, the reporting now includes both adverse effects occurring at normal doses and the consequences of errors. Still, there are other pathways for which drug treatment may cause harm. Examples are drug dependence, ${ }^{13}$ and insufficient effect of medicines that may also occur at normal doses (often referred to as non-responders to the medication). ${ }^{14}$ Moreover, untreated indication has been suggested to cause, for example, drug-related hospitalisations. ${ }^{15}$ Part of these events will be weighed into the decision to initiate drug treatment.

All ADEs included in this study were self-reported; thus, we included preventable and non-preventable ADRs, STE, drug dependence, drug intoxications and untreated indications, as reported by the drug users. Owing to data constraints, it was unfeasible to perform a formal causality assessment for the cases, although reported ADEs were examined to exclude obvious deviations from our aim (eg, drug dependence reported for hypertension treatments). The categories were selected to be mutually exclusive and clarified in the questionnaire: ADRs were described as side effects, STEs were less effective than expected, drug dependence was explained by the inability to stop using the medication, drug intoxications were associated with using too much of the medication, and untreated indications were symptoms for which the respondent considered that he or she would have needed drug treatment. Only reported drug dependence associated with addictive medications were included in the final analyses.

\section{Participants and data collection}

A random sample of 14000 Swedish residents aged 18 years or older was identified by Statistics Sweden from the Swedish adult population (7 382226 individuals) on 1 January 2010 . The sample size was calculated by assuming a 1-month prevalence of $6.4 \%$ for ADRs in Sweden based on a previous study, ${ }^{6}$ a preventable proportion of approximately $10 \%,{ }^{16} 17$ a $60 \%$ response rate ${ }^{6}$ and a maximum width of $\pm 0.3 \%$ for the $95 \%$ CI of the preventable proportion. The estimated sample size (7013) was doubled to enable analyses of predictors and costs. The cross-sectional postal survey was sent in the first week of October 2010. Statistics Sweden distributed the surveys and collected the responses. The envelope contained a letter with information relevant for the informed consent, the questionnaire and a prepaid envelope for returning the questionnaire. Three reminders were sent, one postcard and two with questionnaires. Data collection was closed on 1 February 2011.

The questionnaire encompassed, for the past 30 days, questions on use of healthcare and social services; use of prescribed and over-the-counter medicines as well as herbal remedies; experienced ADEs and perceived 
preventability, consequences and use of healthcare due to ADRs and STEs. The questions of resource use after ADRs or STEs were: Overall, how were you affected by (ADR/STE) during the last 30 days: (seven check boxes for alternative effects)? If you indicated any of (three selected check boxes): how many days (were you unable to conduct your leisure activities/did you stay home from work or equivalent/did you have help from relatives to conduct everyday activities)? How many times during the last 30 days did you have any of the following (healthcare) contacts due to (ADR/STE): (10 types of healthcare encounters indicated, free text space and a check box for those not having had healthcare contacts)? Have your treatment/s been adjusted due to (ADR/STE) during the last 30 days: Yes, a new drug treatment was initiated, with (free text box to indicate drug); Yes, existing drug treatment was changed, for example, stopped or dose adjustment; Yes, a new other treatment was initiated (eg, lifestyle change, surgery/ orthopaedic treatment), namely (free text box to indicate treatment); No, the treatment was not changed? The questionnaire also included demographic and socioeconomic characteristics, and the EQ-5D questionnaire for health-related quality of life. ${ }^{18}$ The questionnaire was piloted with healthcare professionals, individuals from the general public and specific patient groups. All reported ADEs were carefully examined by one of the researchers, a pharmacist (Katja M Hakkarainen), to exclude responses not indicating a suspected symptom or drug. The first author, HG, also a pharmacist with clinical experience, did an independent examination of $10 \%$ of reported ADEs. Differences in opinion were discussed in the research group to reach consensus.

Data from the questionnaire were combined with register data by record linkage, using each respondent's unique personal identification number, by Statistics Sweden. The register data included demographic and socioeconomic variables from the Longitudinal Integration Database for Health Insurance and Labour Market Studies from Statistics Sweden; sick leave and disability pension from the Swedish Social Insurance Agency; as well as filled prescriptions from the Swedish Prescribed Drug Register and hospitalisations from the Swedish Patient Register; the last two are held by the National Board of Health and Welfare.

\section{Direct costs}

Direct costs included used resources, that is, costs resulting from prescription drugs, healthcare, social services and transportation. Direct costs resulting from ADRs or STEs included the costs for prescription drugs and healthcare use caused by either ADRs or STEs reported by the respondents.

Dispensed prescription medicines and associated costs were retrieved from the Swedish Prescribed Drug Register, National Board of Health and Welfare. Costs included both patient copayments and expenses for medicines, and costs paid by the reimbursement scheme.
The prescription drug cost during the study period was the average cost per month calculated from the 2010 annual prescription medicine cost per respondent. Costs of medicine use resulting from ADRs or STEs were the cost of any medicine, reported by the survey respondents to be initiated for treating an ADR or STE, which was dispensed during the study period according to data from the Swedish Prescribed Drug Register. Costs for adjustments to the drug treatment related to, for example, drugs administered from healthcare units, initiation of drug treatment for which the individual already had the medication, initiation of a prescription that was not filled during the period for which we had register data, initiation of over-the-counter drugs or herbal remedies that are not registered, dose adjustments and termination of drug treatment were excluded.

Healthcare use, both overall healthcare use and encounters resulting from ADRs or STEs, were retrieved from the questionnaire, that is, self-reported by the respondents. Results from prespecified questions and from free text were categorised into: phone calls, nurse visits, outpatient physician visits, home healthcare, specialist physician and emergency department visits, visits to other healthcare personnel in somatic care, psychiatrist visits, visits to other healthcare personnel in psychiatric care and hospitalisations. Encounters for healthcare use of relatives, and respondent's donations of blood or tissues, were not included in respondents' healthcare use. Unit costs of healthcare services were based on national statistics on healthcare use and costs. ${ }^{19}$ A visit to other healthcare personnel than physicians was weighted as $40 \%$ of the cost of a physician visit. Phone calls were weighted as one-third of the cost of visiting a nurse, and home healthcare as two times the cost of a nurse visit. Costs paid by the patient were not included in the healthcare costs $(2.3 \%$ of the proceeds to the healthcare producers ${ }^{19}$ ).

Costs for social services included nursing home stay and home-help services reported in the questionnaire. Transportation costs included reported transportation for the disabled and other transportation for healthcare encounters, identified from the questionnaire. Costs for overall use of social services and transportation were based on national statistics. ${ }^{20-22}$

\section{Indirect costs}

Indirect costs included costs resulting from lost productivity for the respondent due to self-reported short-term morbidity (sick leave) and of relatives to the respondents due to informal care. ${ }^{7}$ Sick leave below 2 weeks is not reported in the Social Insurance Agency's register. Owing to the study design, it was not possible to identify deaths during the study period, and there were no respondents initiating disability pension during the study period; therefore, no future indirect costs were estimated. ${ }^{23}$ In addition, productivity loss due to reported long-term sick leave (among those $<70$ years) and disability pension (among those $<65$ years) was 
calculated. Sick leave and disability pension during the study period were identified from the questionnaire, and the costs for lost productivity were measured by the human capital approach, ${ }^{7}$ using national wages statistics and social security contributions. ${ }^{24} 25$

\section{Additional resource use and intangibles}

Visits to dental care and pharmacies, and lost leisure time, were reported descriptively. In addition to the estimated costs for healthcare and drug use, resource use resulting from ADRs and STEs was reported descriptively, including changes to drug therapy not identified as a dispensed medicine in the register during the study period, days of lost leisure time, patients' sick leave and relatives' informal care. Intangible costs were omitted in the cost analysis, but pain and suffering were approximated by the respondents' health-related quality of life using EQ-5D-5L (the EuroQol Group's five-dimension health state questionnaire with five levels of severity) and the UK value sets. ${ }^{26}{ }^{27}$ The EQ-5D-5L is a generic health-related quality of life instrument with five dimensions: mobility, self-care, usual activities, pain/discomfort and anxiety/depression. Each dimension has five levels of severity: no problems/slight problems/moderate problems/severe problems/extreme problems. The responses for each dimension created a health profile for each respondent, which was transferred using the stated value set to the respondents' EQ-5D index value: ranging from dead $(=0)$ to full health $(=1)$. The EQ-5D-5L responses were complemented with results from the EQ-VAS scale (the EuroQol Group's visual analogue scale): from 'Worst imaginable health state' $(=0)$ to 'best imaginable health state' $(=100)$.

\section{Analyses}

Respondents' characteristics were compared with those for non-respondents based on ADE status (table 1), using register data for: age (young adults' age 18-34 years, middle-aged 35-64 years, or individuals above the Swedish retirement age $\geq 65$ years of age), country of birth (Sweden or other than Sweden), educational level (mandatory education, intermediate education, ie, high school and up to 2 years of university education, or high education, ie, more than 2 years of university education), income during 2009, marital status and sex. Main occupation was interpreted from survey responses for occupations, age and income data during 2009. Differences in characteristics were tested for statistical significance $($ at $\mathrm{p}<0.05)$, for respondents with or without ADEs, using $\chi^{2}$ tests.

All unit costs (table 2) were translated to international dollars (Int $\$$ ) using the 2010 purchasing power parity for gross domestic product (1 Int $\$=9.026383$ Swedish krona). ${ }^{28}$ The Int\$ is a hypothetical currency with the same purchasing power as the US dollar (US\$) in the USA, allowing for differences in price levels between countries. $^{29}$ Means and SDs for direct costs, indirect costs and COI were calculated for the 30-day period.
Cost differences were tested for statistical significance (at $\mathrm{p}<0.05$ ), for respondents with or without ADEs, and for $\mathrm{ADE}$ respondents with or without at least one ADR or STE, using a two-tailed $\mathrm{t}$ test with unequal variances. Cost differences and respondents' characteristics were tested for statistical significance (at $\mathrm{p}<0.05$ ), for respondents with at least one ADR or STE, using one-way analysis of variance (for age categories) and a two-tailed $t$ test with unequal variances (for sex). All statistical analyses were made using the STATAV.10.1 software.

\section{Sensitivity analyses}

Sensitivity analyses were made based on the available register data for hospitalisations and respondents' lost productivity from sick leave. Owing to the skewed data, $80 \%$ of the direct costs for respondents with ADEs were reported by $10 \%$ of these respondents (figure 1); a sensitivity analysis proposed in the research plan, based on the IQR of responses, was unachievable. Propensity score matching and analyses were conducted to estimate the direct healthcare costs and indirect costs (excluding informal care), respectively, attributable to ADEs. Propensity scores were calculated by logistic regression from the respondent $\mathrm{ADE}$ status and characteristics (age, sex country of birth, educational level, main occupation, income category and self-reported prescription drug use). Single nearest neighbour matching with callipers (0.01) and without replacement was made using the Psmatch2 module for STATA. ${ }^{30}$ The matching resulted in 1362 pairs of respondents (excluding 15 respondents reporting $\mathrm{ADE}$ ), each respondent with selfreported ADEs matched by the estimated propensity scores to a respondent without ADE, for whom costs were compared. Additional changes from the research plan were limited to how results were reported.

\section{RESULTS}

A total of 7099 questionnaires were collected (response rate $51 \%$ ). At least one ADE was reported by 1377 $(19.4 \%)$ respondents. Of these, $68.5 \%$ (943 respondents) reported at least one ADR or STE. There were statistically significant differences in age $(p<0.05)$, sex $(\mathrm{p}<0.001)$, education $(\mathrm{p}<0.01)$, main occupation $(p<0.001)$ and income $(p<0.001)$, comparing respondents reporting at least one ADE compared with other respondents (table 1). Resource use for respondents with self-reported ADE is presented in table 2. Healthcare was attended by $239(17.4 \%)$ respondents reporting ADEs, of which 96 (40.2\%) were hospitalised or visited a specialist physician (including psychiatrist visits). Among all respondents, 717 (10.1\%) attended healthcare. Resource use among respondents with ADE also included outpatient care in hospitals with other healthcare personnel and primary care visits (eg, nurse visits and physician visits). In addition, home-help services or a nursing home was attended by $51(4.5 \%)$, of the 1138 respondents with ADE that did not attend 
Table 1 Description of the study population and comparison with non-respondents

\begin{tabular}{|c|c|c|c|c|}
\hline & $\begin{array}{l}\text { Respondents } \\
\text { reporting ADE } \\
\text { Total=1377 N (\%) }\end{array}$ & $\begin{array}{l}\text { Respondents not } \\
\text { reporting ADE } \\
\text { Total=5722 N (\%) }\end{array}$ & $\begin{array}{l}\text { All } \\
\text { respondents } \\
\text { Total=7099 N } \\
\text { (\%) }\end{array}$ & $\begin{array}{l}\text { Non-respondents } \\
\text { Total=6832 N (\%) }\end{array}$ \\
\hline \multicolumn{5}{|l|}{ Age (years) ${ }^{\star}$} \\
\hline $18-34$ & $294(21.4)$ & $1036(18.1)$ & $1330(18.7)$ & $2328(34.1)$ \\
\hline $35-64$ & $675(49.0)$ & 2935 (51.3) & $3610(50.9)$ & 3357 (49.1) \\
\hline 65 & $408(29.6)$ & $1751(30.6)$ & $2159(30.4)$ & $1147(16.8)$ \\
\hline \multicolumn{5}{|l|}{$\operatorname{Sex}^{*}$} \\
\hline Men & $528(38.3)$ & $2732(47.7)$ & 3260 (45.9) & $3715(54.4)$ \\
\hline Women & $849(61.7)$ & 2990 (52.3) & $3839(54.1)$ & 3117 (45.6) \\
\hline \multicolumn{5}{|l|}{ Country of birth } \\
\hline Sweden & $1218(88.5)$ & $1276(92.7)$ & $6280(88.5)$ & $5328(78.0)$ \\
\hline Other than Sweden & $159(11.5)$ & $101(7.3)$ & $819(11.5)$ & $1504(22.0)$ \\
\hline \multicolumn{5}{|l|}{ Marital status } \\
\hline Single & 457 (33.2) & $1774(31.0)$ & 2231 (31.4) & 3226 (47.2) \\
\hline Married or registered partnership & $633(46.0)$ & $2872(50.2)$ & 3505 (49.4) & 2424 (35.5) \\
\hline Divorced & $188(13.7)$ & $681(11.9)$ & 869 (12.2) & $802(11.7)$ \\
\hline Widowed & 99 (7.2) & $395(6.9)$ & $494(7.0)$ & $380(5.6)$ \\
\hline \multicolumn{5}{|l|}{ Education*† } \\
\hline Mandatory education & $240(17.6)$ & $1144(20.1)$ & $1499(21.1)$ & $1804(26.4)$ \\
\hline Intermediate education & $655(48.0)$ & $2840(49.9)$ & $3438(48.4)$ & $3483(51.0)$ \\
\hline High education & $471(34.5)$ & $1706(30.0)$ & $2115(29.8)$ & $1342(19.6)$ \\
\hline \multicolumn{5}{|l|}{ Main occupation* $\ddagger$} \\
\hline Employee & $584(43.0)$ & $2783(49.0)$ & 3367 (47.8) & NA \\
\hline Company owner & $58(4.3)$ & $351(6.2)$ & $409(5.8)$ & NA \\
\hline Student & $81(6.0)$ & $290(5.1)$ & $371(5.3)$ & NA \\
\hline Retired & $391(28.8)$ & 1697 (29.9) & $2088(29.7)$ & NA \\
\hline $\begin{array}{l}\text { On long-term sickness absence } \\
\text { or disability pensioner }\end{array}$ & $131(9.7)$ & $202(3.6)$ & $333(4.7)$ & NA \\
\hline Other & $112(8.3)$ & $359(6.3)$ & $471(6.7)$ & NA \\
\hline \multicolumn{5}{|l|}{ Income in $2009^{*}$} \\
\hline $\operatorname{lnt} \$ \leq 13848$ & $322(23.4)$ & 1046 (18.3) & 1368 (19.3) & 2248 (32.9) \\
\hline Int\$ $13848-22490$ & $299(21.7)$ & 1162 (20.3) & 1461 (20.6) & 1267 (18.5) \\
\hline Int\$ 22490-30245 & $290(21.1)$ & 1192 (20.8) & 1482 (20.9) & 1279 (18.7) \\
\hline Int\$ 30245-39661 & 259 (18.8) & 1235 (21.6) & $1494(21.0)$ & 1109 (16.2) \\
\hline Int\$ 39662 $\geq$ & 207 (15.0) & 1087 (19.0) & 1294 (18.2) & 929 (13.6) \\
\hline
\end{tabular}

healthcare, while $164(14.4 \%)$ reported informal care and $131(11.5 \%)$ had stayed home from work.

The economic burden for individuals with selfreported ADEs were $($ mean $\pm \mathrm{SD}, 95 \%$ CI) Int $\$ 521.2$ \pm 1485.7 , Int $\$ 442.7$ to 599.8 , of which direct costs were measured at Int\$ $349.8 \pm 1328.7$, Int $\$ 279.6$ to 420.0 $(67.1 \%)$ and indirect costs were Int\$ $171.4 \pm 537.1$, Int $\$$ 143.0 to 199.8 (32.9\%; table 3 and figure 2). The average COI was higher among those reporting ADEs compared with respondents without ADEs (COI: Int\$ $208.5 \pm 876.3$, Int $\$ 185.8$ to $231.2 ; \mathrm{p}<0.001)$. Productivity loss due to long-term sick leave and disability pension increased the indirect costs by Int $\$ 353.5 \pm 1149.6$ for those with self-reported ADEs and by Int $\$ 133.0 \pm 728.5$ for other respondents $(p<0.001)$. The COI of respondents with ADR or STE was Int\$ 560.9 \pm 1439.8 , Int $\$ 468.9$ to 652.9 . Resource use among respondents with self-reported ADEs, or resulting from ADRs or STEs, occurred both in hospitals and outside of hospital in primary care. For respondents with ADEs, $12 \%$ of the healthcare costs originated from primary care nurse or general practitioner visits, while the remaining costs were equally distributed to other outpatient care $(44 \%)$ and hospitalisations $(44 \%)$, while the proportions were: $15 \%, 44 \%$ and $41 \%$ among all respondents.

Among all respondents with at least one self-reported ADR or STE, the average direct costs resulting from ADRs and STEs were Int\$ 31.7 $\$ 8.5$, Int $\$ 15.0$ to 48.4 . The resulting costs correspond to $8.7 \%$ of the direct costs and $12.5 \%$ of the costs of prescription drugs and 
Table 2 Resource use in respondents with ADEs, and unit costs for the resources

\begin{tabular}{|c|c|c|c|}
\hline & $\begin{array}{l}\text { Respondents reporting ADE and } \\
\text { resource use } \\
\text { Total=1377 N (\% of total) }\end{array}$ & $\begin{array}{l}\text { Quantity of resources used } \\
\text { N or hours }\end{array}$ & $\begin{array}{l}\text { Unit cost } \\
\text { (Int\$) }\end{array}$ \\
\hline \multicolumn{4}{|l|}{ Direct costs } \\
\hline Dispensed medicines* & $1218(88.5)$ & 26436 & - \\
\hline \multicolumn{4}{|l|}{ Healthcare use: } \\
\hline Phone calls & $106(7.7)$ & 267 & 18.5 \\
\hline Nurse visits & $93(6.8)$ & 182 & 55.4 \\
\hline Physician visits & $92(6.7)$ & 124 & 138.6 \\
\hline Specialist physician and ED visits & $91(6.6)$ & 191 & 313.0 \\
\hline Home healthcare & $6(0.4)$ & 39 & 110.9 \\
\hline Other somatic visits & $52(3.8)$ & 159 & 55.4 \\
\hline Psychiatrist visits & $4(0.3)$ & 4 & 407.5 \\
\hline Other psychiatric visits & $49(3.6)$ & 120 & 163.0 \\
\hline Hospitalisations & $16(1.2)$ & 20 & 5036.7 \\
\hline \multicolumn{4}{|l|}{ Social services: } \\
\hline Home-help services & $52(3.8)$ & 1851 & 45.7 \\
\hline Nursing homes & $19(1.4)$ & 480 & 173.9 \\
\hline \multicolumn{4}{|l|}{ Transportation: } \\
\hline Services for the disabled & $38(2.8)$ & 420 & 29.8 \\
\hline Other transportation & $240(17.4)$ & 2793 & 2.5 \\
\hline \multicolumn{4}{|l|}{ Indirect costs } \\
\hline \multicolumn{4}{|l|}{ Sick leave (by age) (years) } \\
\hline $18-24$ & $24(23.1)$ & 1000 & 12.1† \\
\hline $25-34$ & $35(18.4)$ & 1690 & $15.7 \dagger$ \\
\hline $35-44$ & $36(19.1)$ & 1852 & $18.2 \dagger$ \\
\hline $45-54$ & $29(13.0)$ & 1186 & $18.5 \dagger$ \\
\hline $55+$ & $39(5.8)$ & 2062 & $18.2 \dagger$ \\
\hline Informal care & $228(16.6)$ & 2871 & $17.2 \dagger$ \\
\hline \multicolumn{4}{|c|}{$\begin{array}{l}\text { Resource use quantities, percentages and costs are rounded. } \\
\text { *Based on register data. } \\
\text { †The unit cost indicated was the average wage per hour in each age group, }{ }^{24} \text { which was then multiplied by the general payroll tax. For } \\
\text { residents }<26 \text { years of age, the general payroll tax was } 15.49 \% \text { and for residents } \geq 26 \text { years of age it was } 31.42 \%{ }^{25} \text { For informal care, the } \\
\text { indicated unit cost was the average wage per hour, which was then multiplied by the general payroll tax for residents } \geq 26 \text { years of age. } \\
\text { ADE, adverse drug events; ED, emergency department; Int\$, international dollars; N, number; NA, not applicable; } Q \text {, quartile. }\end{array}$} \\
\hline
\end{tabular}

healthcare use for those with ADRs or STEs. The average direct costs resulting from ADRs were Int\$ $0.5 \pm 4.1$ for prescription drugs and Int $\$ 17.3 \pm 159.0$ for healthcare use, for those with ADRs. For STEs, the average direct costs were Int\$ $1.4 \pm 8.7$ and Int\$ 33.9 \pm 281.2 , respectively. Extrapolated to the Swedish population, the annual direct costs resulting from ADRs or STEs were Int\$370.1 million. There were no statistically significant differences in COI for respondents with ADRs or STEs, or direct costs resulting from the ADRs or STEs, by age or sex (table 4).

Additional resource use attributed to ADRs by 554 respondents, reported during the 30 days study period, included: 90 medication changes not registered in the Swedish Prescribed Drug Register, 1448 days of lost leisure time $(n=117), 529$ days of sick leave $(n=61)$ and 600 days with informal care $(n=49)$. For STEs, additional resource use among the 539 respondents included: 116 medication changes, 2510 days of lost leisure time $(n=187), 857$ days of sick leave $(n=88)$ and 1171 days with informal care $(n=92)$. The health-related quality-of-life scores were significantly lower for respondents with ADEs compared with other respondents (figure 3): the EQ-5D summary estimates were $0.84 \pm 0.18$ versus $0.71 \pm 0.22(\mathrm{p}<0.001)$, and results from the visual analogue scale were $69.79 \pm 20.69$ versus $81.17 \pm 16.94(\mathrm{p}<0.001)$.

\section{Sensitivity analyses}

The hospitalisation rate reported in the survey (19 respondents reported 24 hospitalisations during the study period) was compared with the hospitalisation rate identified from register data: 85 respondents had 101 hospitalisations covering a total of 365 days during the 5 weeks before answering the survey. Thus, the sensitivity of the reporting of hospitalisations in the questionnaire was $59 \%$ and the specificity was $99 \%$ compared with register data. Among the 85 respondents, 24 hospitalisations lasted only 1 day or night, 10 hospitalisations occurred less than 1 week before the respondent's questionnaire was registered at Statistics Sweden, and 7 hospitalisations identified from the register were duplicate registrations based on transfers between hospitals or departments. For sick leave, the sensitivity was $12 \%$ and 


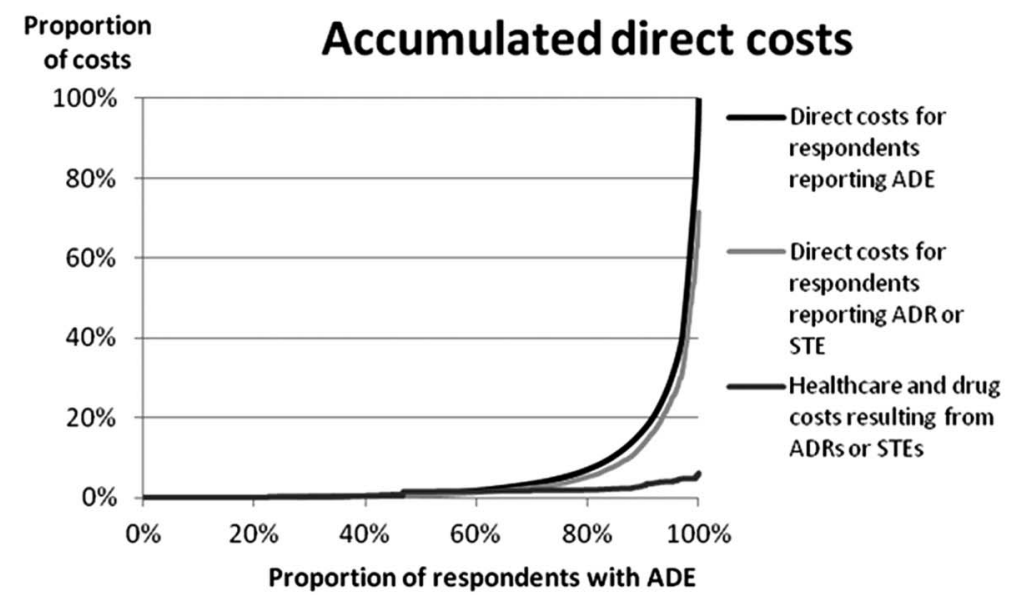

Abbreviations: $\mathrm{ADE}=$ adverse drug events; $\mathrm{ADR}=$ adverse drug reaction; $\mathrm{STE}=$ sub-therapeutic effect of medication therapy.

Figure 1 Accumulated direct costs of individuals with self-reported adverse drug events, including the subgroup reporting adverse drug reactions or subtherapeutic effects of medication therapies.

the specificity was $99 \%$, compared with register data, with 55 persons identified from both the register and the questionnaire. Of the 70 respondents identified from the register but not from the questionnaire, 25 were reported to be on long-term sickness absence, seeking a job or on parental leave, whereas 45 persons had not reported the sick leave identified in the register. Of those 390 respondents reporting sick leave that was not identified in the register, 306 reported sick leave of less than 2 weeks (which in Sweden is paid by the employer and is not registered), 7 had disability pension and the remaining 77 individuals did not receive sickness benefit for their absence. Additional deviations were not possible to explain using the available data.

According to the propensity score analyses, the attributable costs for ADEs were Int\$ 99.4 for direct healthcare costs and Int\$221.5 for indirect costs (excluding informal care).

\section{DISCUSSION}

In this study, the societal COI of 1377 individuals with self-reported ADEs was Int\$ 717750.4 and the direct costs resulting from self-reported ADRs and STEs in 943

Table 3 Average cost of illness for respondents with and without self-reported ADEs

\begin{tabular}{|c|c|c|}
\hline & $\begin{array}{l}\text { COI with } A D E \\
N=1377 \text { average } \pm S D\end{array}$ & $\begin{array}{l}\text { COI without } A D E \\
N=5722 \text { average } \pm S D\end{array}$ \\
\hline Dispensed prescription medicines $(\operatorname{Int} \$)^{\star}$ & $48.6 \pm 119.0$ & $24.7 \pm 103.3$ \\
\hline Healthcare use $(\operatorname{Int} \$)^{\star}$ & $164.9 \pm 935.3$ & $40.1 \pm 360.7$ \\
\hline Social services (Int\$) & $122.1 \pm 778.8$ & $83.6 \pm 673.5$ \\
\hline Transportation $(\operatorname{Int} \$)^{\star}$ & $14.3 \pm 84.8$ & $6.9 \pm 67.2$ \\
\hline Total direct cost $(\operatorname{Int} \$)^{\star}$ & $349.8 \pm 1328.7$ & $155.2 \pm 805.3$ \\
\hline Productivity loss, sick leave (Int\$)* & $124.4 \pm 496.2$ & $41.1 \pm 272.8$ \\
\hline Informal care† $(\operatorname{Int} \$)^{\star}$ & $47.1 \pm 187.0$ & $12.1 \pm 89.3$ \\
\hline Total indirect cost $(\operatorname{Int} \$)^{*}$ & $171.4 \pm 537.1$ & $53.3 \pm 290.9$ \\
\hline Cost of illness $(\operatorname{Int} \$)^{\star}$ & $521.2 \pm 1485.7$ & $208.5 \pm 876.3$ \\
\hline \multicolumn{3}{|l|}{ Other resource use: } \\
\hline Over-the-counter drugs, number & $1.6 \pm 1.5$ & $1.0 \pm 1.9$ \\
\hline Natural remedies, number & $0.5 \pm 1.0$ & $0.3 \pm 1.2$ \\
\hline Lost leisure time, days & $3.7 \pm 7.8$ & $1.0 \pm 4.2$ \\
\hline Prevalent disability pension, $\mathrm{n}(\%)$ & $135(9.8)$ & $242(4.2)$ \\
\hline$E Q-5 D$ index value & $0.71 \pm 0.22$ & $0.84 \pm 0.18$ \\
\hline Self-rated health by EQ-VAS & $69.8 \pm 20.7$ & $81.2 \pm 16.9$ \\
\hline \multicolumn{3}{|c|}{$\begin{array}{l}\text { Resource use quantities, percentages and costs are rounded. } \\
\text { *Statistically significant cost difference between respondents with/without ADEs }(p<0.05) \text {. } \\
\text { †Of the } 546 \text { respondents reporting informal care, } 56 \text { respondents were excluded from the analyses since the amount of care (days and hours) } \\
\text { was not reported. } \\
\text { ADE, adverse drug events; EQ-5D, The EuroQol Group's five dimension health state questionnaire with five levels of severity; EQ-VAS, The } \\
\text { EuroQol Group's visual analogue scale; Int\$, international dollars; N, population size. }\end{array}$} \\
\hline
\end{tabular}




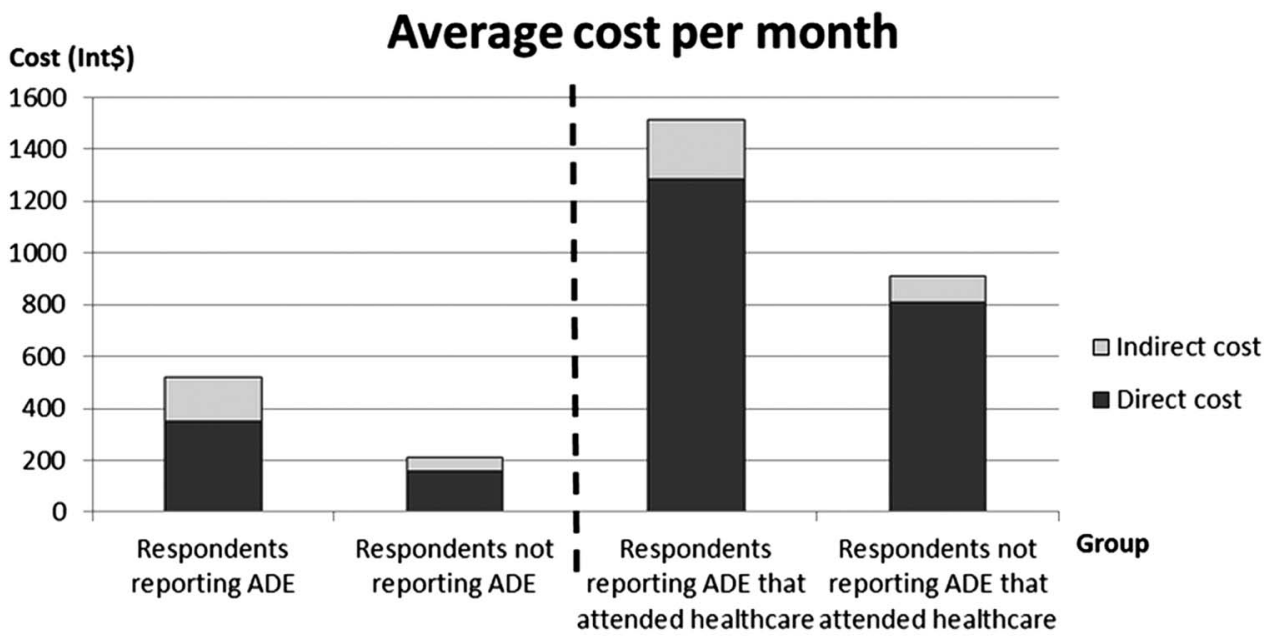

Abbreviations: $\mathrm{ADE}=$ adverse drug events; Int $\$=$ international dollars.

Figure 2 The average monthly cost of illness of respondents based on reported adverse drug event status and healthcare attendance, divided into direct and indirect costs.

individuals were Int\$29 935.9. Thus, the extrapolated annual direct costs in Sweden resulting from ADRs and STEs were Int $\$ 370$ million in 2010. Our results suggest that ADEs also cause costs outside hospitals, as well as for patients not attending hospitals. Thus, studies limited to drug-related admission will underestimate the economic impact in society. We have also found an association between the occurrence of ADEs and high overall COI that needs to be further analysed in future studies. Those reporting ADEs were more extensive users of prescription drugs, healthcare resource use, transportation services and informal care, compared with other respondents. Moreover, they had more shortterm sick leave and disability pension than other

Table 4 Distribution of costs among respondents with self-reported ADRs or STEs*, including cost of illness (all-cause morbidity) and direct costs resulting from self-reported ADRs or STEs

\begin{tabular}{|c|c|c|c|}
\hline & $\begin{array}{l}\text { Respondents with ADR } \\
\text { or STE } \\
\text { N (\%) }\end{array}$ & $\begin{array}{l}\text { Average cost of illness for } \\
\text { respondents with ADR or STE } \\
\text { Average } \pm S D \text {, Int } \$\end{array}$ & $\begin{array}{l}\text { Direct cost resulting from } \\
\text { ADRs or STEs } \\
\text { Average } \pm S D \text {, Int\$ }\end{array}$ \\
\hline \multicolumn{4}{|c|}{ Total resource use among respondents with ADRs or STEs $(\mathrm{N}=943)$} \\
\hline Cost of illness & - & $560.9 \pm 1439.8$ & NA \\
\hline Direct costs & - & $(365.6 \pm 1279.4)$ & NA \\
\hline Indirect costs & - & $(195.3 \pm 564.7)$ & NA \\
\hline \multicolumn{4}{|l|}{ Age (years) } \\
\hline $18-34$ & $209(22.2)$ & $556.5 \pm 1580.8$ & $31.4 \pm 241.7$ \\
\hline $35-64$ & $473(50.2)$ & $511.5 \pm 1154.4$ & $41.5 \pm 326.9$ \\
\hline $65+$ & $261(27.7)$ & $653.9 \pm 1754.8$ & $14.3 \pm 77.3$ \\
\hline \multicolumn{4}{|l|}{ Sex } \\
\hline Men & $346(36.7)$ & $486.4 \pm 1182.8$ & $32.1 \pm 232.4$ \\
\hline Women & 597 (63.3) & $604.0 \pm 1568.9$ & $31.5 \pm 276.7$ \\
\hline \multicolumn{4}{|l|}{ Type of ADE $\ddagger$} \\
\hline ADR & $554(58.7)$ & $659.0 \pm 1613.6$ & $36.6 \pm 290.8$ \\
\hline STE & 539 (57.2) & $566.0 \pm 1446.1$ & $47.5 \pm 335.5$ \\
\hline \multicolumn{4}{|l|}{$\begin{array}{l}\text { Self-reported } \\
\text { preventability }\end{array}$} \\
\hline Preventable§ & 208 (22.1) & $717.6 \pm 1897.3$ & $56.8 \pm 342.9$ \\
\hline Non-preventable & 735 (77.9) & $516.5 \pm 1279.2$ & $24.7 \pm 232.7$ \\
\hline \multicolumn{4}{|c|}{$\begin{array}{l}\text { Percentages and costs are rounded. } \\
\text { *Include respondents with at least one self-reported ADR or STE. } \\
\text { tInclude resource use reported for both ADRs and STEs. } \\
\text { fCategories overlap; both includes respondents with at least one self-reported ADR or STE, respectively. } \\
\text { §Includes respondents with at least one preventable self-reported ADR or STE. } \\
\text { ADR, adverse drug reaction; Int\$, international dollars; N, subgroup sample size; NA, not applicable; STE, subtherapeutic effect of medicatior } \\
\text { therapy. }\end{array}$} \\
\hline
\end{tabular}




\section{Average Health-related quality of life score}

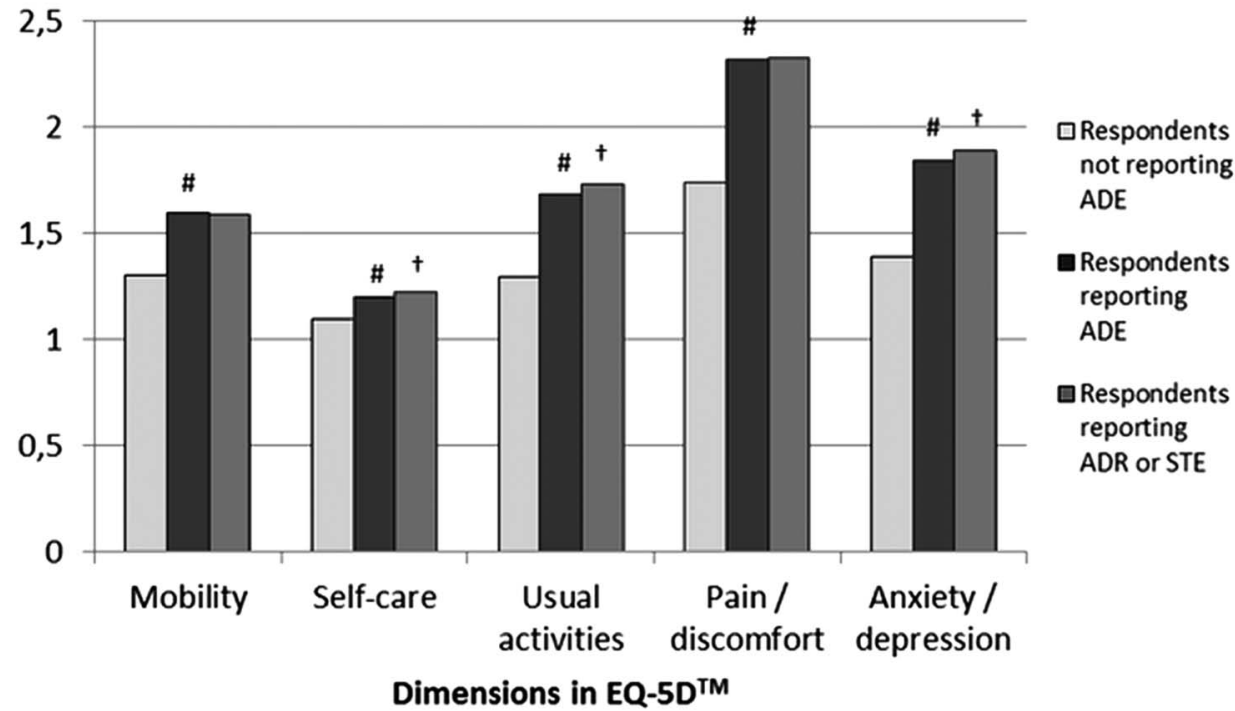

Abbreviations: ADE, adverse drug events; EQ-5D, The EuroQol Group's five dimension health state questionnaire with five levels of severity.

Figure 3 Dimensions of health-related quality of life, health profile results from the EQ-5D instrument, the severity reported for each domain using the 1-5-point Likert scale (from 'no problem' to 'extreme problem'), categorised based on the reported adverse drug event status.

respondents. Much of this increase in resource use will be due to comorbidities, and will be involved in causing ADEs, but although not quantified as costs caused by ADEs, some respondents also reported that they had experienced sick leave, informal care and lost leisure time resulting from ADRs and STEs.

The strengths of this study include a large number of respondents. However, certain groups were underrepresented among respondents, for example, young adults, men and those born in another country than Sweden. It is possible that the decision to respond is associated with health status, with either severely ill patients or healthy residents being less prone to respond. Previous research suggests that the bias is mainly towards survey respondents being healthier than those not responding. ${ }^{31}$ Other causes for incorrect estimation of the costs for ADEs in our study were the limitation to ADE status and used resources reported by the respondents. Responses were carefully examined to exclude responses not indicating a suspected symptom or drug; there may be symptoms reported that were, for example, resulting from the underlying disease rather than the drug use, and other relevant symptoms perceived by the respondent to be either not related to the drug use or not included in the five ADE categories included in the questionnaire. Previous research has shown that there is little overlap between ADEs reported by patients and by physicians ${ }^{32}$; thus, we may underestimate the prevalence and resulting resource use of ADEs by not including the physicians' experiences. However, previous research has identified patients themselves as important actors in reporting adverse events, also due to drug use. $^{33}$ Moreover, the general public is today expected to monitor drug use and report suspected ADRs. Thus, we believe that the self-reported ADEs reported in our survey adds a relevant aspect to the knowledge of drug use outcomes, although it needs to be acknowledged that the events were self-reported and not assessed for causality by any experienced clinician. The sensitivity analyses included comparing resource use with what was reported in national registers, including data for hospitalisations and sick leave. The register analyses indicated an under-reporting rather than an overestimation of the resource use. Moreover, our main cause for underestimating COI may be the limitation of indirect costs to short-term sick leave and informal care. In a recent study of the total COI in Sweden, short-term sickness represented approximately $30 \%$ of the indirect costs and $17 \%$ of the COI. ${ }^{34}$ Lost wages and household production have been reported to cause $47 \%$ of the total costs in patients discharged from hospital with adverse events (of which ADEs corresponded to $32 \%$ of all costs). ${ }^{35}$ Our design (time frame and data collection method) did not allow the estimation of indirect costs from disability pension and mortality, thus underestimating the economic impact of ADEs.

Our ADE definition was more inclusive than those of some previous studies, ${ }^{3}$ although the included categories' associations with drug treatment and drug-related problems have been acknowledged previously. On the 
basis of the ADE definition applied, the prevalence and associated costs will differ. Limiting the inclusion to only, for example, ADRs and STEs resulted in a prevalence of $13 \%$ in the Swedish population, which is equal to the previously estimated ambulatory care prevalence of ADEs. ${ }^{36}$ Our estimated 1-month prevalence of ADRs of $7.8 \%$ was similar to the 2-week prevalence $(6.4 \%)$ identified in a previous survey in the Swedish general public. ${ }^{6}$

Our results suggest that the drug users experience ADEs and associated consequences that have not so far been included in studies of injuries resulting from medical intervention related to drugs. Thus there is a need to further explore and identify the causes, consequences and possibilities for prevention of experienced ADEs. In our study, less than one-fifth of respondents with ADEs attended healthcare during the study period, and one-fifth of those with ADRs or STEs reported drug-related healthcare contacts. A previous study has reported that three quarters of elderly participants experiencing ADRs contacted a physician and $5 \%$ were also hospitalised due to ADR during a 1-year study period, ${ }^{37}$ but the disparity may depend on the length of the study period and the age of the respondents. Our average direct costs resulting from ADRs (Int\$37) were, as expected, low compared with previous estimates of approximately Euro 2800 for ADRs in patients attending hospitals. ${ }^{38}$ However, the small proportion of respondents reporting healthcare contacts due to their ADR or STE (with no respondent reporting hospitalisation due to an ADR or STE), and the short study period, makes direct comparisons impossible. Our estimated average direct cost for respondents with ADEs that attended healthcare during the study period (Int\$1283) was similar to the attributable charges previously reported for ADEs identified after a visit to ambulatory care: US\$ 926 (2006 value) ${ }^{39}$

According to our results, there is a need for increased awareness about the impact of ADEs which does not result in the patient attending hospital. Lundkvist and Jönsson $^{40}$ have previously remarked on the balance between the costs of ADRs and benefits of drug treatments, and the two costs of ADRs: costs resulting from treating ADRs and from avoiding ADRs. Moreover, additional efforts are needed to handle STE, which seem to be just as common and costly as ADRs. According to our results, the balancing of costs and benefits for drugs will also include the occurrence of and costs associated with insufficient effects of medicines, although not all these costs will be possible to prevent or avoid through improved drug treatments. Since ADE status seems to be associated with high overall COI and incurs healthcare resource use, many of these patients should be possible to identify in the healthcare system, even when ADE in itself may not be the main cause of resource use. On the basis of the perspective of a decision or analysis, our results indicate that such costs will also occur outside the healthcare system, for example, for sick leave, informal care and lost leisure time. The result was strengthened by the propensity score analyses indicating that there were both direct healthcare costs and indirect costs attributable to ADEs. Thus, the patient's views and experiences of drug treatments need to be further addressed in treatment decisions.

Future research is needed to further analyse the relationship between ADEs and the associated resource use, to identify when and how the resource use occurs, as well as the true relationship between ADEs and the overall COI. There is also a need to examine the indirect costs resulting from ADEs, since our study could only briefly describe sick leave and informal care resulting from ADRs and STEs. Moreover, the resource use identified from patients' self-reports should be contrasted by population-based estimates of ADEs and the associated resource use identified by healthcare professionals, to enable further analyses of the clinical and economic impact of ADEs, identify high-risk patients and study the causes and consequences of ADEs in the general public.

\section{CONCLUSIONS}

To our knowledge, this is the first study to estimate COI of ADEs in the general public. Our results show that selfreported ADRs and STEs cause resource use both in hospitals and primary care. Moreover, ADEs seem to be associated with a high overall COI from the societal perspective, when comparing respondents with and without ADEs. There is a need to further examine the relationships between ADEs and associated resource use and overall COI, respectively, and to study the indirect costs resulting from ADEs.

\section{Author affiliations}

${ }^{1}$ Nordic School of Public Health NHV, Gothenburg, Sweden

${ }^{2}$ Department of Learning, Informatics, Management and Ethics-LIME, Karolinska Institutet, Stockholm, Sweden

${ }^{3}$ Department of Drug Research/Clinical Pharmacology, Faculty of Health Sciences, Linköping University / Department of Clinical Pharmacology, County Council of Östergötland, Linköping, Sweden

${ }^{4}$ Akademistatistik - Centre for applied biostatistics, Sahlgrenska Academy, University of Gothenburg, Gothenburg, Sweden

${ }^{5}$ Medical Products Agency, Uppsala, Sweden

${ }^{6}$ Section of Social Medicine, Department of Public Health and Community Medicine, Sahlgrenska Academy, University of Gothenburg, Gothenburg, Sweden

Acknowledgements We wish to thank the survey respondents for taking the time to share their experience with us.

Contributors KAS was the principal investigator. $\mathrm{HG}$ did the analyses and drafted the manuscript. AC, AKJ, CR, HG, KAS and MP contributed to the study design and development of the questionnaire, data analysis and interpretation of the results and commented on the draft. Also, Katja M Hakkarainen, Staffan Hägg, Johnny Pettersson and Annika Yeiter contributed to the study design, and to the development and piloting of the questionnaire. Tatiana Zverkova Sandström contributed to the data analysis. All authors had full access to all data. $H G$ is the guarantor.

Funding The research is part of the DRUMS project (Drug-related morbidity and mortality in Sweden: prevalence, preventability and costs) funded by an unrestricted grant from the National Corporation of Swedish Pharmacies (Apoteket $A B$ ). The study sponsor had no role in the study design; in the collection, analysis and interpretation of data; in the writing of the article; and 
in the decision to submit it for publication. The researcher's work was independent from that of the sponsor. All authors, external and internal, had full access to all the data (including statistical reports and tables) in the study and can take responsibility for the integrity of the data and the accuracy of the data analysis.

Competing interests All authors had financial support from the National Corporation of Swedish Pharmacies (Apoteket AB) for the submitted work.

Ethics approval The study received ethical approval from the Regional Ethical Review Board in Gothenburg (approval reference number: 238-10), in 2010. The questionnaire cover letter included information about how and why the research was conducted, contact information and how to withdraw. Informed consent was implied by returning the questionnaire. The questionnaire and the cover letter were developed in accordance with the declaration of Helsinki. The ethical approval did not include an approval to share individual responses or register data publicly.

Provenance and peer review Not commissioned; externally peer reviewed.

Data sharing statement No additional data are available.

\section{REFERENCES}

1. Bates DW, Boyle DL, Vander Vliet MB, et al. Relationship between medication errors and adverse drug events. J Gen Intern Med 1995; 10:199-205.

2. Einarson TR. Drug-related hospital admissions. Ann Pharmacother 1993;27:832-40.

3. Krähenbühl-Melcher A, Schlienger R, Lampert M, et al. Drug-related problems in hospitals: a review of the recent literature. Drug Saf 2007;30:379-407.

4. Rodríguez-Monguió R, Otero MJ, Rovira J. Assessing the economic impact of adverse drug effects. Pharmacoeconomics 2003;21:623-50.

5. Gyllensten H, Jönsson AK, Rehnberg C, et al. How are the costs of drug-related morbidity measured? A systematic literature review. Drug Saf 2012;35:207-19.

6. Isacson D, Johansson L, Bingefors K. Nationwide survey of subjectively reported adverse drug reactions in Sweden. Ann Pharmacother 2008;42:347-53.

7. Segel JE, ed. Cost-of-IIIness studies-a primer. RTI-UNC Center of Excellence in Health Promotion Economics, 2006:1-39.

8. Hakkarainen KM, Andersson Sundell K, Petzold M, et al. Self-reported adverse drug events equally prevalent across age groups-a population-based survey in Sweden. Manuscript submitted for publication.

9. Aronson JK, Ferner RE. Clarification of terminology in drug safety. Drug Saf 2005;28:851-70.

10. Yu K, Nation R, Dooley M. Multiplicity of medication safety terms, definitions and functional meanings: when is enough? Qual Saf Health Care 2005;14:358-63.

11. Edwards IR, Aronson JK. Adverse drug reactions: definitions, diagnosis, and management. Lancet 2000;356:1255-9.

12. European Parliament, Council of the European Union. Directive 2010/84/EU of the European Parliament and of the Council of 15 December 2010 amending, as regards pharmacovigilance, Directive 2001/83/EC on the Community code relating to medicinal products for human use. OJ 2010;L 348:74-99.

13. Young AM, Glover N, Havens JR. Nonmedical use of prescription medications among adolescents in the United States: a systematic review. J Adolesc Health 2012;51:6-17.

14. Taylor S, Abramowitz JS, McKay D. Non-adherence and non-response in the treatment of anxiety disorders. J Anxiety Disord 2012;26:583-9.

15. Al-Olah $\mathrm{YH}, \mathrm{Al}$ Thiab KM. Admissions through the emergency department due to drug-related problems. Ann Saudi Med 2008;28:426-9.

16. Gandhi TK, Seger DL, Bates DW. Identifying drug safety issues: from research to practice. Int J Qual Health Care 2000;12:69-76.

17. Gandhi TK, Weingart SN, Borus J, et al. Adverse drug events in ambulatory care. N Engl J Med 2003;348:1556-64.

18. EuroQol Group. EuroQol-a new facility for the measurement of health-related quality of life. The EuroQol Group. Health Policy 1990;16:199-208.
19. Swedish Association of Local Authorities and Regions Editor Statistik om hälso- och sjukvård samt regional utveckling 2010. Sveriges kommuner och landsting, Stockholm, 2011:1-216. ISBN:978-91-7164-683-5. Swedish.

20. Swedish Association of Local Authorities and Regions Editor Kostnad per brukare: jämförelser mellan kommuner inom omsorg om äldre och personer med funktionsnedsättning: utfall 2010. Sveriges kommuner och landsting, Stockholm, 2011:39. ISBN: 978-91-7164-722-1. Swedish.

21. Transport Analysis Editor. Special transport service and inter-municipal transport service 2010. Trafikanalys, Stockholm 2011. Report: 2011:16. Swedish.

22. Transport Analysis Editor. Local and regional public transport 2010 Trafikanalys, Stockholm, 2011. Report: 2011:19. Swedish

23. Lindgren B. Costs of illness in Sweden 1964-1975. Lund, Sweden: Lund University, 1981.

24. Statistics Sweden. Genomsnittlig grund- och månadslön samt kvinnors lön i procent av mäns lön efter sektor, yrke (SSYK), kön och ålder. År 2005-2010. http://www.ssd.scb.se/databaser/makro/ Visavar.asp?yp=tansss\&xu=C9233001\&omradekod=AM\& huvudtabell=LonYrkeAlder4\&omradetext=Arbetsmarknad\&tabelltext= Genomsnittlig+grund\%2D+och+m\%E5nadsl\%F6n+samt+kvinnors+l $\% \mathrm{~F} 6 \mathrm{n}+\mathrm{i}+$ procent+av+m\%E4ns+l\%F6n+efter+sektor $\% 2 \mathrm{C}+\mathrm{yrke}+\%$ 28SSYK\%29\%2C+k\%F6n+och+\%E5Ider\%2E+\%C5r\&preskat=O \&prodid=AM0110\&deltabell=\&deltabellnamn=Genomsnittlig+grund\% $2 \mathrm{D}+\mathrm{och}+\mathrm{m} \% \mathrm{E} 5$ nadsl $\% \mathrm{~F} 6 \mathrm{n}+\mathrm{samt}+\mathrm{kvinnors}+\mathrm{l} \% \mathrm{~F} 6 \mathrm{n}+\mathrm{i}+$ procent+av+m $\%$ E4ns+l\%F6n+efter+sektor\%2C+yrke+\%28SSYK\%29\%2C+k\%F6n +och+\%E5Ider\%2E+\%C5r\&innehall=Antal\&starttid=2005 \&stopptid=2010\& Fromwhere=M\&lang $=1$ \&langdb=1 (accessed 6 Mar 2012).

25. Statistics Sweden. Mer om Arbetskostnadsindex (AKI). Swedish http://www.scb.se/Pages/Standard__23066.aspx (accessed 26 Nov 2012)

26. Herdman M, Gudex C, Lloyd A, et al. Development and preliminary testing of the new five-level version of EQ-5D (EQ-5D-5L). Qual Life Res 2011;20:1727-36.

27. EuroQol Group. EQ-5D-5L Crosswalk Value Sets. 2012. http://www. euroqol.org/about-eq-5d/valuation-of-eq-5d/eq-5d-5l-value-sets.html (accessed 26 Nov 2012).

28. Organisation for economic co-operation and development. PPPs and exchange rates. http://stats.oecd.org/Index.aspx?

DataSetCode=CPL\# (accessed 24 Sep 2012).

29. Evans DB, Edejer TT, Adam T, et al. Methods to assess the costs and health effects of interventions for improving health in developing countries. BMJ 2005;331:1137-40.

30. Leuven E, Sianesi B, eds. PSMATCH2: Stata module to perform full Mahalanobis and propensity score matching, common support graphing, and covariate imbalance testing. Boston College Department of Economics. Report: April 2012 revision, 2003. http:// ideas.repec.org/c/boc/bocode/s432001.html

31. Suominen S, Koskenvuo K, Sillanmaki L, et al. Non-response in a nationwide follow-up postal survey in Finland: a register-based mortality analysis of respondents and non-respondents of the Health and Social Support (HeSSup) Study. BMJ Open 2012;2:e000657.

32. Morimoto T, Gandhi TK, Seger AC, et al. Adverse drug events and medication errors: detection and classification methods. Qual Saf Health Care 2004;13:306-14.

33. Zhu J, Stuver SO, Epstein AM, et al. Can we rely on patients' reports of adverse events? Med Care 2011;49:948-55.

34. Ramsberg J, Ekelund M. Stuprörstänkande gör samhällets kostnader för ohälsa onödigt höga. Ekonomisk debatt 2011;39:41-53. Swedish.

35. Thomas EJ, Studdert DM, Newhouse JP et al Costs of medical injuries in Utah and Colorado. Inquiry 1999;36:255-64.

36. Taché SV, Sönnichsen A, Ashcroft DM. Prevalence of adverse drug events in ambulatory care: a systematic review. Ann Pharmacother 2011;45:977-89.

37. Chrischilles EA, Segar ET, Wallace RB. Self-reported adverse drug reactions and related resource use. A study of community-dwelling persons 65 years of age and older. Ann Intern Med 1992;117:634-40.

38. Gautier S, Bachelet $\mathrm{H}$, Bordet $\mathrm{R}$, et al. The cost of adverse drug reactions. Expert Opin Pharmacother 2003;4:319-26.

39. Burton MM, Hope C, Murray MD, et al. The cost of adverse drug events in ambulatory care. AMIA Annu Symp Proc 2007:90-3.

40. Lundkvist J, Jönsson B. Pharmacoeconomics of adverse drug reactions. Fundam Clin Pharmacol 2004:18:275-80. 